\title{
Sand Floor for Farmed Blue Foxes: Effects on Claws, Adrenal Cortex Function, Growth and Fur Properties
}

\author{
Leena Ahola, Tarja Koistinen, and Jaakko Mononen \\ Department of Biosciences, University of Kuopio, P.O. Box 1627, 70211 Kuopio, Finland \\ Correspondence should be addressed to Leena Ahola, leena.ahola@uku.fi
}

Received 22 May 2008; Revised 21 November 2008; Accepted 10 February 2009

Recommended by Marcel Eens

\begin{abstract}
Farmed blue foxes (Vulpes lagopus) are traditionally housed on mesh floors where they are unable to perform certain speciesspecific behaviours, such as digging, which may compromise the animals' welfare. This study describes how a possibility to use in-cage sand floor affects welfare-related variables like growth of the claws, adrenal cortex function, and fur properties in juvenile blue foxes. The foxes $(N=32)$ were housed in male-female sibling pairs in an outdoor fur animal shed in cage systems consisting of two traditional fox cages. For the eight male-female sibling pairs of the Control group, there was a mesh floor in both cages of each cage system, whereas for the eight pairs of the Sand group there was a mesh floor in one cage and a 30-40 cm deep earth floor in the other cage. The results show that sand floor is beneficial for the wearing of the claws of foxes. Furthermore, an early experience of sand floor may have positive effects on the foxes' fur development. The results, however, also suggest that there might appear welfare problems observed as disturbed claw growth and increased adrenal cortex activation if foxes that are once provided with clean and unfrozen sand floor are not allowed to enjoy this floor all the time.
\end{abstract}

Copyright (C) 2009 Leena Ahola et al. This is an open access article distributed under the Creative Commons Attribution License, which permits unrestricted use, distribution, and reproduction in any medium, provided the original work is properly cited.

\section{Introduction}

According to the nature-based approach to animal welfare (see [1]), the welfare of production animals can be improved by providing the animals with natural housing conditions that enable them to behave species-specifically. However, it is impracticable to provide production animals with completely natural living conditions. Nonetheless, although it may not be possible to allow production animals to live in completely natural conditions, we still may provide them with some important environmental features rooted in their natural living environment. With respect to farmed blue foxes (Vulpes lagopus, formerly Alopex lagopus), one of these important key features is the floor material used in their housing systems.

Farmed blue foxes are traditionally housed in plastic coated wire mesh floor cages. However, recent research has shown that an earthen floor, a natural surface for the wild $V$. lagopus, may have some importance for blue foxes (e.g., [27]). However, recent research on the effects of sand or earth floors on the behaviour and physiology of blue foxes has suffered from several confounding factors. In the previous experiments, blue foxes have been farmed in male-male pairs $[8,9]$ or singly $[4,6,10,11]$ which differs from the normal farming practices where foxes are housed most often in male-female pairs. For example, single housing per se may jeopardise the welfare of social animals [12], especially when they are juvenile (for farmed silver foxes Vulpes vulpes see [13]). Therefore, in singly housed foxes, the effects of an earth floor on the animals' welfare may be exaggerated due to the fact that the animals are suffering social deprivation. Other factors that may have confounded earlier experiments have been reviewed in Koistinen et al. [14]. Koistinen et al. [14] assessed blue foxes' behaviour and preferences (i.e., feelings-based welfare, see [1]) between a mesh floor and a sand floor in a study where the flaws of these previous studies were corrected. Despite the modified study design, the results of the study [14] turned out to be practically the same as the results from the earlier studies: blue foxes preferred, based on their time allocation, the mesh floor to the sand floor but nonetheless the sand floor seemed to have at least some enrichment value for the foxes. This emerged when the foxes with access to the sand floor were shown to express less stereotypic behaviours than the foxes with access 
only to the mesh floor. Furthermore, a rebound-effect was observed in some behaviours on the sand floor (e.g., digging) in the foxes with access to the sand floor after a sand floor deprivation.

The present study that is a part of the study of Koistinen et al. [14] continued to assess welfare effects of continuous access to sand floor under normal farming conditions in farmed blue foxes. Whereas Koistinen et al. [14] assessed blue foxes' behaviour and preferences (i.e., feelings-based welfare, see [1]) between mesh and sand floors, in this study we evaluated how a sand floor experience or the lack of this experience can affect the blue foxes' biological functioning (functioning-based welfare, see [1]). First, we studied the effects of the sand floor on the growth of the claws. In the wild, foxes' claws wear down while, for example, digging and walking on ground. On farms, however, claws of the foxes that are housed on mesh floor do not wear and the claws may grow very long [15]. Long claws can become caught in the mesh of the cage and break, exposing the foxes to digit inflammations which impacts on both the functioning-based and feelings-based welfare of the animals. Therefore, the animal welfare legislation regulating farmed fur animals [16] requires that the claws should be cut when too long. Furthermore, the European Convention's [17] Recommendations concerning fur animals states that "animals (foxes) will be kept in such way that their claws are in good condition." One way to ensure that those claws do not grow too long is to provide the foxes with floor materials that enhance the wearing of claws, for example, sand or earth. Accordingly, we hypothesised that the possibility to interact with sand floor could prevent the overgrowth of the foxes' claws.

Secondly, we studied how the sand floor experience affects the stress physiology and production of the blue foxes. Our hypothesis was that if sand floor was important for the welfare of farmed blue foxes (i.e., as suggested by the feelings-based results of the study [14]), the lack of sand floor or the deprivation of a once-experienced sand floor would increase the activity of the adrenal cortex (e.g., [18]) and reallocate animals' biological resources from growth and fur development to coping with the stress [19].

Accordingly, the present study aimed to assess whether sand could be used as a feasible floor material for farmed foxes under normal farming conditions, without compromising the welfare of these animals. Possible welfare-related effects were assessed by measuring the claw growth, adrenal cortex function, growth and fur characteristics in the juvenile blue foxes with access either to only a mesh floor or to both a mesh and sand floors. The results will be discussed in the light of the foxes' behaviour during the present study [14].

\section{Materials and Methods}

The procedures used in the present study are in compliance with the European Communities Council Directive of 24 November 1986 (86/609/EEC). The experiment was approved by the Institutional Animal Care and Use Committee of the University of Kuopio (Licence number 03-59).
2.1. Animals and Housing. There were 16 male-female sibling pairs of farmed juvenile blue foxes, born in May, in the present study. The foxes were housed throughout the study in an outdoor fur shed. For the first four weeks of their lives, each pair was housed with its mother and other siblings as a fox family in a traditional mesh floored fox cage $(115 \times$ $105 \times 70 \mathrm{~cm}, \mathrm{~L} \times \mathrm{W} \times \mathrm{H})$ furnished with a nest box, a mesh platform, a wooden gnawing object, and a feeding tray. When the cubs were four weeks old, the families were divided randomly into two experimental groups. For both experimental groups, cage systems were constructed from two traditional fox cages that were connected together with an opening $(22.5 \times 27.5 \mathrm{~cm}, \mathrm{~W} \times \mathrm{H})$ through the walls between the cages. In the Control group, the families were housed from the cubs' age of four weeks until the cubs' age of eight weeks in double cage systems where both available cages had a mesh floor. In the Sand group, the families were housed in double cage systems where the bottom of one cage was made of mesh and the bottom of the other cage was replaced with a $35-40 \mathrm{~cm}$ deep layer of sand (particle size $<10 \mathrm{~mm}$ ). The nest boxes were removed from the cages at the cubs' age of seven weeks. At the cubs' age of eight weeks, the mother and other cubs except for the randomly chosen experimental male and female cubs were removed from the double cage systems; that is, thereafter there was only the male-female sibling pair in each double cage system. Accordingly, there were eight male-female sibling pairs in both the Control group and the Sand group.

Since the present experiment studied also the foxes' preferences for sand floor (see [14]), the foxes in the Sand group were deprived of the sand floor for 14 days in early September. During this deprivation period, each pair of foxes in the Sand group had access to a double cage system where both available cages had a mesh floor. The foxes in the Control group had access to mesh floored double cage systems during the whole study (for detailed description of the deprivation procedure see [14]).

Dirty sand was removed from the sand floor and the sand box was refilled with clean sand immediately after weaning and once in early October, soon after the deprivation period.

The health of the animals was checked daily. The foxes were fed according to the recommendations given by the Finnish Fur Breeders' Association with fresh fur animal feed twice a day until mid-November, thereafter once a day. The daily feed portion per animal was the same for each group and was delivered equally between the available cages. Water was available ad libitum, except in subzero temperatures (November-December) when fresh water was provided twice a day.

2.2. Measured Parameters. Claw lengths (from the cuticle to the claw tip) of all digits from the right front and back paw were measured at the cubs' age of eight weeks, in early September (during the first week of the 14-day deprivation period), early October, early November, and at pelting in mid-December. The numbers of broken claws in the right front and right back paw were counted in early September, early October, and at pelting in mid-December. 
Body mass of the experimental foxes was measured at the cubs' age of eight weeks (i.e., at weaning in June-July), in early October, and at pelting in mid-December.

Prior to pelting in mid-December, the foxes were injected ( $1 \mathrm{~mL}$ i.m.) with synthetic corticotropin (ACTH) $(0.25 \mathrm{mg}$ tetracosactide, Synacthen $0.25 \mathrm{mg} / \mathrm{mL}$, Novartis Finland Oy, Espoo, Finland). Two hours after the injection, the foxes were euthanised by electrocution according to the methods recommended by the Standing Committee of the European Convention for the Protection of Animals Kept for Farming Purposes [17]. Blood samples were immediately drawn by cardiac puncture. The serum cortisol level, as a maximum response to ACTH administration $[18,20]$, was analysed with a competitive immunoassay technique (Coat-A-Count Cortisol Assay by Diagnostic Products Corporation, Los Angeles, Calif, USA).

After pelting, the adrenals were removed from the carcasses, cleaned, and weighed. The pelts were fleshed, cleaned, dried, and sent for auction. Professional fur graders at the Finnish Fur Sales Ltd (Helsinki, Finland) evaluated the mass and overall quality of the furs using a 10-point scale (1: poorest, 10: best).

2.3. Statistical Analyses. Statistical analyses were performed using SPSS statistical software (SPSS for windows 14.0). Since the two siblings in each double cage system were dependent on each other, General Linear Model (GLM) for repeated measures was used to analyse differences between the groups in all measured variables. For the body mass data, the Huynh-Feldt epsilon, a correction formula in the GLM procedure in SPSS, was used in calculating the new degrees of freedom and significances in the within-subjects effects Month and Sex*Month due to the sphericity problems in these within-subjects effects. Since the number of claw breakages per animal was low in all measures, the data on the number of broken claws was analysed as a sum variable of claw breakages observed in both front and back paws in September, October, and December. Thus, the maximum possible number of claw breakages was 24 per animal. Since the claw length did not differ significantly between the four digits in the preliminary GLM model $(P>.1)$, the claw lengths were ultimately analysed using the mean length of claws of all four digits. $P$-values smaller than .05 were considered as statistically significant, $.1<P<.05$ as tendencies and $P>.1$ as nonsignificant (NS).

\section{Results}

No animals were found injured or sick during the whole study.

More claw breakages per animal were observed in the Control group $(3.9 \pm 1.7$, mean \pm standard deviation, $S D)$ than in the Sand group $(1.3 \pm 1.2)(F(1,14)=12.78, P=$ $.003)$. Sex had no significant effect on the total number of observed claw breakages $(2.4 \pm 2.9$ and $2.8 \pm 1.6$ breakages in males and females, resp., $F(1,14)=0.33$, NS). There was no significant interaction between the experimental group and sex in the total number of claw breakages $(F(1,14)=0.59$, NS).

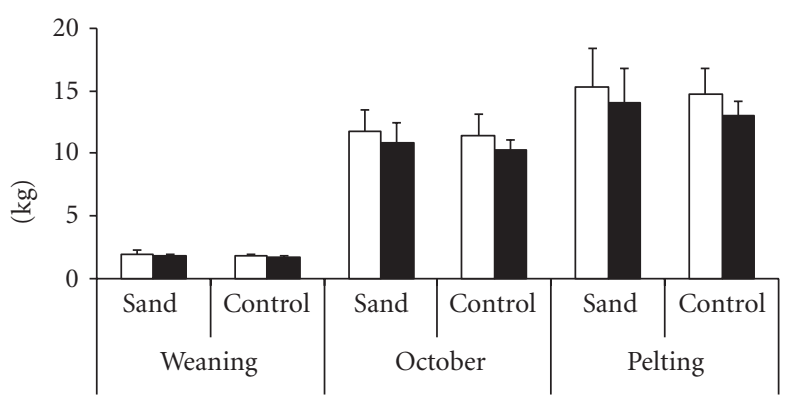

Figure 1: Body mass (kg, mean $+\mathrm{SD}$ ) of juvenile blue foxes in the Sand and Control groups at the cubs' age of eight weeks (weaning), in early October and at pelting (mid-December). Open bars: males, solid bars: females. Main effects (GLM for repeated measures): Group $F(1,14)=0.64$, NS; Sex $F(1,14)=9.78, P=.007$; Month $F(2,21)=489.54, P=.000 ;$ Sex $*$ Month $F(1,18)=7.50, P=.009$, other interactions NS.

There was no significant main effect of the experimental group on the claw length (Table 1). The males had longer claws, especially in the Control group, than the females. Furthermore, the claws were, in general, longer in the right front paw than in the right back paw. The claws remained shorter in the Sand group than in the Control group until November-December. In the Control group, the claws of the front paw grew until November and became shorter thereafter whereas the claws of the back paw started to shorten already in September-October. In the Sand group, the claws of the front and back paw wore and grew steadily and only a small decrease in the claw lengths was observed in the Sand group in the October claw inspection compared to the situation in September.

There was no statistically significant difference in the body mass of the animals between the Sand group and Control group (Figure 1). In general, the males were heavier than the females, especially at the end of the growing season.

The left adrenal was heavier in the Sand group than in the Control group and in the males than in the females (Figure 2). No significant differences between the experimental groups and sexes were observed in the mass of right adrenal and the total mass of adrenals. There was no significant difference between the experimental groups and sexes in the serum cortisol level after ACTH administration (Sand group: $299 \pm 103$ and $345 \pm 89 \mathrm{nmol} / \mathrm{L}$ in the males and females, resp.; Control group: $308 \pm 108$ and $314 \pm 68 \mathrm{nmol} / \mathrm{L}$ in the males and females, resp., Group $F(1,14)=0.09$, NS, $\operatorname{Sex} F(1,14)=0.65$, NS, Sex* Group $F(1,14)=0.38, \mathrm{NS})$.

The mass and overall quality of furs tended to be better in the Sand group than in the Control group (Table 2). Furthermore, the mass and overall quality of furs was better in the males than in the females. In particular, the females in the Control group had poor mass and overall quality of furs.

\section{Discussion}

The present results revealed that the foxes' claws remained shorter in the Sand group than in the Control group until 
TABle 1: Mean claw length $(\mathrm{mm}$, mean $\pm \mathrm{SD})$ of front and back right paw at weaning, in September, October, November, and December in juvenile blue foxes in the Sand and Control groups. Main effects (GLM for repeated measures): Group F(1,14) = 0.18, NS; Sex $F(1,14)=7.60, P=.015 ;$ Month $F(4,56)=206.05, P=.000 ;$ Paw $F(1,14)=183.74, P=.000$. Interactions: Sex* Group $F(1,14)=3.50$, $P=.082 ;$ Month $*$ Group $F(4,56)=4.06, P=.006$; Paw $*$ Group $F(1,14)=20.19, P=.001$; Paw $*$ Month $F(4,56)=2.94, P=.028$; Month $*$ Paw $*$ Group $F(4,56)=7.50, P=.000$; other interactions NS.

\begin{tabular}{|c|c|c|c|c|c|}
\hline & Weaning & September & October & November & December \\
\hline \multicolumn{6}{|c|}{ Male, front paw } \\
\hline Sand & $12.0 \pm 1.3$ & $20.6 \pm 3.4$ & $19.7 \pm 3.3$ & $23.1 \pm 4.0$ & $25.4 \pm 2.4$ \\
\hline Control & $11.8 \pm 1.2$ & $23.2 \pm 1.3$ & $24.6 \pm 2.2$ & $25.8 \pm 1.8$ & $24.4 \pm 3.8$ \\
\hline \multicolumn{6}{|c|}{ Male, back paw } \\
\hline Sand & $10.6 \pm 1.1$ & $19.4 \pm 2.1$ & $19.4 \pm 1.9$ & $22.1 \pm 2.0$ & $22.2 \pm 2.0$ \\
\hline Control & $9.7 \pm 1.7$ & $20.1 \pm 2.0$ & $20.0 \pm 1.7$ & $21.2 \pm 1.4$ & $21.1 \pm 1.7$ \\
\hline \multicolumn{6}{|c|}{ Female, front paw } \\
\hline Sand & $11.3 \pm 1.1$ & $21.0 \pm 1.4$ & $20.4 \pm 3.1$ & $23.8 \pm 2.1$ & $25.1 \pm 2.6$ \\
\hline Control & $11.7 \pm 1.2$ & $22.8 \pm 2.1$ & $24.0 \pm 2.5$ & $23.0 \pm 1.8$ & $22.5 \pm 3.3$ \\
\hline \multicolumn{6}{|c|}{ Female, back paw } \\
\hline Sand & $10.1 \pm 0.9$ & $19.4 \pm 2.4$ & $18.3 \pm 1.9$ & $21.3 \pm 2.0$ & $21.4 \pm 1.8$ \\
\hline Control & $9.3 \pm 1.0$ & $18.5 \pm 1.4$ & $18.0 \pm 1.6$ & $19.5 \pm 2.4$ & $20.6 \pm 3.2$ \\
\hline
\end{tabular}

TABLE 2: Mass and overall quality of the furs (10-point scale; 1 = poorest, $10=$ best; mean \pm SD) of juvenile blue foxes in the Sand and Control groups.

\begin{tabular}{|c|c|c|c|c|c|c|c|}
\hline & \multicolumn{2}{|c|}{ Sand } & \multicolumn{2}{|c|}{ Control } & \multirow{2}{*}{ Group } & \multirow{2}{*}{ Sex } & \multirow{2}{*}{ Group $x$ Sex } \\
\hline & Male & Female & Male & Female & & & \\
\hline Mass $^{(a)}$ & $6.1 \pm 1.2$ & $5.4 \pm 1.2$ & $5.6 \pm 1.8$ & $3.6 \pm 1.3$ & $\begin{array}{c}F(1,13)=3.18 \\
P=.098\end{array}$ & $\begin{array}{c}F(1,13)=23.68 \\
P=.000\end{array}$ & $\begin{array}{c}F(1,13)=4.89 \\
P=.045\end{array}$ \\
\hline Quality $^{(\mathrm{a})}$ & $5.4 \pm 1.2$ & $4.9 \pm 1.2$ & $4.7 \pm 1.9$ & $2.7 \pm 1.6$ & $\begin{array}{c}F(1,13)=4.24 \\
P=.060\end{array}$ & $\begin{array}{c}F(1,13)=12.64 \\
P=.004\end{array}$ & $\begin{array}{c}F(1,13)=4.55 \\
P=.063\end{array}$ \\
\hline
\end{tabular}

${ }^{\text {(a) }}$ GLM for repeated measures.

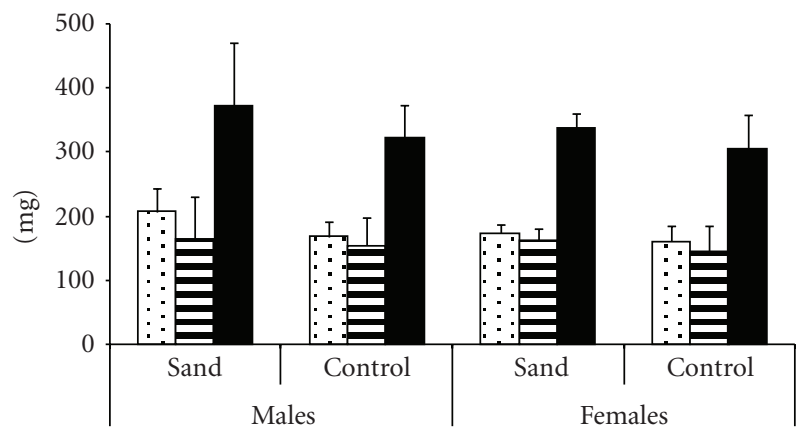

Figure 2: Mass (mg, mean $+\mathrm{SD}$ ) of left (spotted bars) and right (lined bars) adrenal and total mass of adrenals (black bars) of juvenile blue foxes in the Sand and Control groups. Main effects (GLM for repeated measures): Left adrenal Group $F(1,13)=7.70$, $P=.016, \operatorname{Sex} F(1,13)=5.88, P=.031$, Sex*Group $F(1,13)=$ 2.30, NS; Right adrenal Group $F(1,13)=0.70$, NS, Sex $F(1,13)=$ 0.14 , NS, Sex $*$ Group $F(1,13)=0.06$, NS; Total mass of adrenals Group $F(1,13)=2.97$, NS, Sex $F(1,13)=1.52$, NS, Sex $*$ Group $F(1,13)=0.17$, NS.

November. This result indicates that sand floor is beneficial in promoting the wearing of the claws. However, although digging or walking on any rough flooring wears the claws, these activities also most probably increase the blood flow to the digits which in turn not only increases the growth rate but also strengthens the claws (see [21]). The effect of different kinds of activities on claw length was apparent in the present study, that is, longer claws in the front than in the back paw digits (similarly to the results in [11]). Accordingly, when the foxes were able to manipulate the sand floor or at least utilised the sand floor [14], the claws of the foxes in the Sand group wore "naturally." The (fast-growing) claws of the Sand group foxes were then broken after (or during the last week of) the sand floor deprivation period in September. Thereafter the claws of the Sand group foxes again grew and wore "naturally." This continued until the sand floors were becoming soiled with faeces and frozen in November-December. At that time, the Sand group foxes spent significantly less time on the sand floor than in September (on the sand floor $2.0 \pm 0.5$ and $11.1 \pm 2.1 \%$ of all observations in December and September before the deprivation period, resp., [14]). In December, the claws did not wear but continued to grow rapidly due to the earlier stimulation. As a result, in December the claws of the Sand group foxes were longer than the claws of the Control group foxes. Accordingly, our hypothesis that sand floor would be beneficial for the wearing of the claws was correct, but only with one proviso: sand floors are beneficial for the claw health and growth only if the foxes are permanently provided with the kind of sand floor that the foxes are willing to utilise. 
The effects of sand or earth floors on the adrenal cortex activity in blue foxes have been assessed in earlier studies by measuring the total mass of adrenals (e.g., $[10,11])$. In general, no significant differences have been detected in the total adrenal mass between foxes with and without access to an earth floor. However, there is evidence that it is the left adrenal in particular that is more sensitive to stressful events or stressful conditions [22-24]. Here we found that the left adrenals were heavier in the Sand group foxes than in the Control group foxes. Accordingly, this result suggests that the foxes in the Sand group had experienced more stress than the foxes in the Control group. It could be hypothesised that the Sand group foxes experienced the sand floor as an aversive surface. One indication in support of this proposal might be that the Sand group foxes were seen on the sand floor cage in less than $20 \%$ of the total observations [14]. In the Control group, in contrast, the observations were evenly distributed between the two available cages. However, one must bear in mind that the Sand group foxes were never forced to stay on the sand floors, they always had access to the mesh floor, too. Furthermore, mere time allocation between available options is an insufficient basis on which to draw conclusions about animals' needs (see [14]). Therefore, another, more likely explanation is that the increased left adrenal mass in the Sand group was attributable to the lack of the clean and unfrozen sand floor in the latter part of the study period. In other words, when the sand floor was clean and unfrozen, the foxes were able or willing to perform different activities in the sand, for example, digging, scratching, and sniffing. In September and October, approximately $50 \%$ of observations from the total observations of these behaviours were observed to occur on the sand floor [14]. When the sand floor became soiled and frozen in December, the Sand group foxes spent less time on the sand floor than previously, and less than $25 \%$ of the total observations of digging or scratching and sniffing behaviours occurred on the sand floor [14]. The hypothesis that it was the lack of (clean and unfrozen) sand floor that enlarged the foxes' adrenals is supported by the observation of a rebound-effect in digging and sniffing behaviour when these foxes were reunited with this resource after the deprivation period in September [14], that is, the animals place value on access to a clean sand floor. Accordingly, the present result on the adrenal mass, as well as the feelings-based welfare results [14], suggests that if farmed blue fox cubs are once provided with a clean and unfrozen sand floor, they should be allowed to enjoy this floor for the rest of their lives (cf. digging in farmed blue foxes, [5]). This could, however, prove to be impossible or at least highly demanding to implement in northern climates with subzero temperatures during the long winter months.

The ACTH challenge test did not reveal any significant differences between the experimental groups in their adrenal cortex activities. This apparent discrepancy between the adrenal mass and ACTH challenge test results is not a unique finding in welfare studies (see, e.g., [25, 26]). Furthermore, in the present study, the animals were injected with the more rapidly acting Synacthen instead of the more slowly acting Synacthen Depot that has been used earlier in studies focusing on the welfare of farmed foxes (e.g., $[20,25]$ ); that is, the true peak cortisol concentration may have occurred already before the blood samples were drawn. Therefore, the present ACTH challenge test results should be evaluated with some caution.

With regard to the measured production variables, there were no statistical differences in the body masses of the foxes in the two experimental groups. The Sand group foxes tended to have better mass and overall quality of furs than the Control group foxes. Blue foxes start to replace their summer coat with a new winter pelage already in August [27]; that is, the foxes have to be prepared to invest their biological resources in fur development throughout their growing season. The slightly better mass and overall quality of furs in the Sand group foxes might suggest that the Sand group foxes could afford to invest their resources in fur development and growth during their early lives, that is, from August onwards, whereas the Control group foxes were investing more of their resources in coping (see [19] for discussion about the "biological cost of stress") with their every-day-lives, including the housing environment without a possibility to interact with sand floor.

In conclusion, the present results suggest that access to sand floor is beneficial for the wearing of the claws of blue foxes. Furthermore, an early experience of sand floor may have positive effects on the animals' fur development. However, these results also suggest that if foxes are once provided with clean and unfrozen sand floor, they should be allowed to have access to this kind of floor all the time. Otherwise there may be welfare problems such as disturbed claw growth and increased adrenal cortex activation. It may prove to be impossible or at least highly demanding to allow foxes to enjoy access to clean and unfrozen sand floor under the normal fox farming practices in northern climates with subzero temperatures for several months.

\section{Acknowledgments}

The authors wish to thank the anonymous reviewers for their constructive comments. The study was supported by the Fur Animal Welfare Council and Finnish Fur Breeders' Association. The authors are grateful to the staff of the research station for animal care, to Martti Hallikainen, Maija Miskala, Teija Pyykönen, and Antti Turunen for practical assistance on the farm and Hobo Kukkonen for laboratory analyses.

\section{References}

[1] D. Fraser, D. M. Weary, E. A. Pajor, and B. N. Milligan, "A scientific conception of animal welfare that reflects ethical concerns,” Animal Welfare, vol. 6, no. 3, pp. 187-205, 1997.

[2] H. Korhonen and P. Niemelä, "Choices of farm foxes for raised wire mesh cage and ground pen," Applied Animal Behaviour Science, vol. 54, no. 2-3, pp. 243-250, 1997.

[3] H. Korhonen, L. Jauhiainen, and P. Niemelä, "Effect of enlarged cage space and access to earthen floor on locomotor and digging activity of blue foxes," Agricultural and Food Science in Finland, vol. 8, no. 3, pp. 253-263, 1999. 
[4] H. T. Korhonen, L. Jauhiainen, and P. Niemelä, "Effect of space allowance and earthen flooring on behaviour of farmed blue foxes," Acta Ethologica, vol. 4, no. 1, pp. 11-21, 2001.

[5] H. T. Korhonen, L. Jauhiainen, L. Kokkonen, and T. Rekilä, "Digging in farmed blue foxes: essential or not?" Annals of Animal Science, vol. 4, no. 2, pp. 405-419, 2004.

[6] M. Harri, S. Kasanen, J. Mononen, and J. Sepponen, "Preferences of farmed blue foxes for different floor types," Behavioural Processes, vol. 49, no. 2, pp. 111-119, 2000.

[7] T. Koistinen, L. Ahola, and J. Mononen, "Blue foxes' motivation for access to an earth floor measured by operant conditioning," Applied Animal Behaviour Science, vol. 107, no. 3-4, pp. 328-341, 2007.

[8] H. Korhonen, L. Jauhiainen, P. Niemelä, M. Harri, and R. Sauna-aho, "Physiological and behavioural responses in blue foxes (Alopex lagopus) : comparisons between space quantity and floor material," Animal Science, vol. 72, no. 2, pp. 375-387, 2001.

[9] H. T. Korhonen, P. Niemelä, and L. Jauhiainen, "Effect of space and floor material on the behaviour of farmed blue foxes," Canadian Journal of Animal Science, vol. 81, no. 2, pp. 189197, 2001.

[10] H. Korhonen, P. Niemelä, L. Jauhiainen, and T. Tupasela, "Effects of space allowance and earthen floor on welfarerelated physiological and behavioural responses in male blue foxes," Physiology and Behavior, vol. 69, no. 4-5, pp. 571-580, 2000.

[11] H. T. Korhonen, L. Jauhiainen, and T. Rekilä, "In-cage sandbox as a ground substitute for farmed blue foxes (Alopex lagopus): effects on digging activity and welfare," Canadian Journal of Animal Science, vol. 83, no. 4, pp. 703-712, 2003.

[12] M. Mendl and R. C. Newberry, "Social conditions," in Animal Welfare, M. C. Appleby and B. O. Hughes, Eds., pp. 191-203, CAB International, Wallingford, UK, 1997.

[13] L. Ahola, Effects of social and physical housing environment on the welfare in silver foxes (Vulpes vulpes), Doctoral dissertation, Faculty of Natural and Environmental Sciences, Kuopio University, Kuopio, Finland, 2002.

[14] T. Koistinen, L. Ahola, and J. Mononen, "Blue foxes' (Alopex lagopus) preferences between earth floor and wire mesh floor," Applied Animal Behaviour Science, vol. 111, no. 1-2, pp. 38-53, 2008.

[15] V. Pedersen, "Length, growth and wearing of claws among farmed blue foxes (Alopex lagopus) with and without nest boxes," Scientifur, vol. 14, no. 2, pp. 101-103, 1990.

[16] Ministry of Agriculture and Forestry, "Decision on animal welfare requirements for fur animals," (16/VFD/1999), 1999.

[17] European Convention, "Standing committee of the European Convention for the Protection of animals kept for farming purposes (T-AP). Recommendations concerning fur animals," T-AP (96) 19, June 1999.

[18] D. Broom and K. G. Johnson, Stress and Animal Welfare, Chapman \& Hall, London, UK, 1993.

[19] G. P. Moberg, "Biological response to stress: implication for animal welfare," in The Biology of Animal Stress, G. P. Moberg and J. A. Mench, Eds., pp. 1-21, CAB International, Wallingford, UK, 2000.

[20] T. Rekilä, M. Harri, L. Jalkanen, and J. Mononen, "Relationship between hyponeophagia and adrenal cortex function in farmed foxes," Physiology \& Behavior, vol. 65, no. 4-5, pp. 779$783,1998$.

[21] A. S. Geyer, N. Onumah, H. Uyttendaele, and R. K. Scher, "Modulation of linear nail growth to treat diseases of the nail,"
Journal of the American Academy of Dermatology, vol. 50, no. 2, pp. 229-234, 2004.

[22] H. S. Siegel and P. B. Siegel, "The relationship of social competition with endocrine weights and activity in male chickens," Animal Behaviour, vol. 9, no. 3-4, pp. 151-158, 1961.

[23] E. Szigethy, Y. Conwell, N. T. Forbes, C. Cox, and E. D. Caine, "Adrenal weight and morphology in victims of completed suicide," Biological Psychiatry, vol. 36, no. 6, pp. 374-380, 1994.

[24] L. N. Trut, L. A. Prasolova, A. V. Kharlamova, and I. Z. Plyusnina, "Directional left-sided asymmetry of adrenals in experimentally domesticated animals," Bulletin of Experimental Biology and Medicine, vol. 133, no. 5, pp. 506-509, 2002.

[25] L. Ahola, M. Harri, S. Kasanen, J. Mononen, and T. Pyykönen, "Effects of group housing in an enlarged cage system on growth, bite wounds and adrenal cortex function in farmed blue foxes (Alopex lagopus)," Animal Welfare, vol. 9, no. 4, pp. 403-412, 2000.

[26] L. Ahola, J. Mononen, T. Pyykönen, and M. Miskala, "Group housing of farmed silver fox cubs," Animal Welfare, vol. 15, no. 1, pp. 39-47, 2006.

[27] L. Blomstedt, "Pelage cycle in blue fox (Alopex lagopus): a comparison between animals born early and late in the season," Acta Agriculturae Scandinavica, Section A, vol. 48, no. 2, pp. 122-128, 1998. 

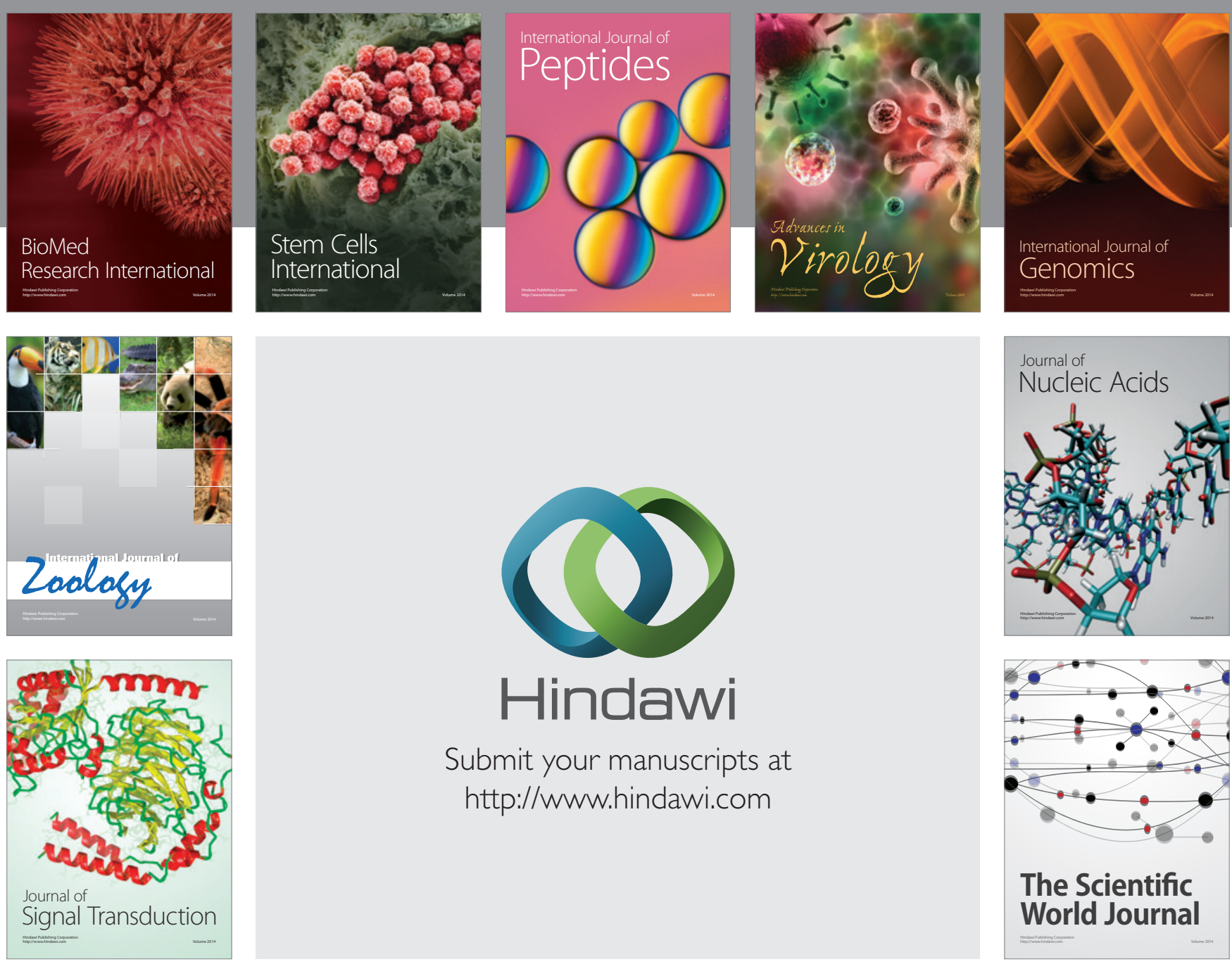

Submit your manuscripts at

http://www.hindawi.com
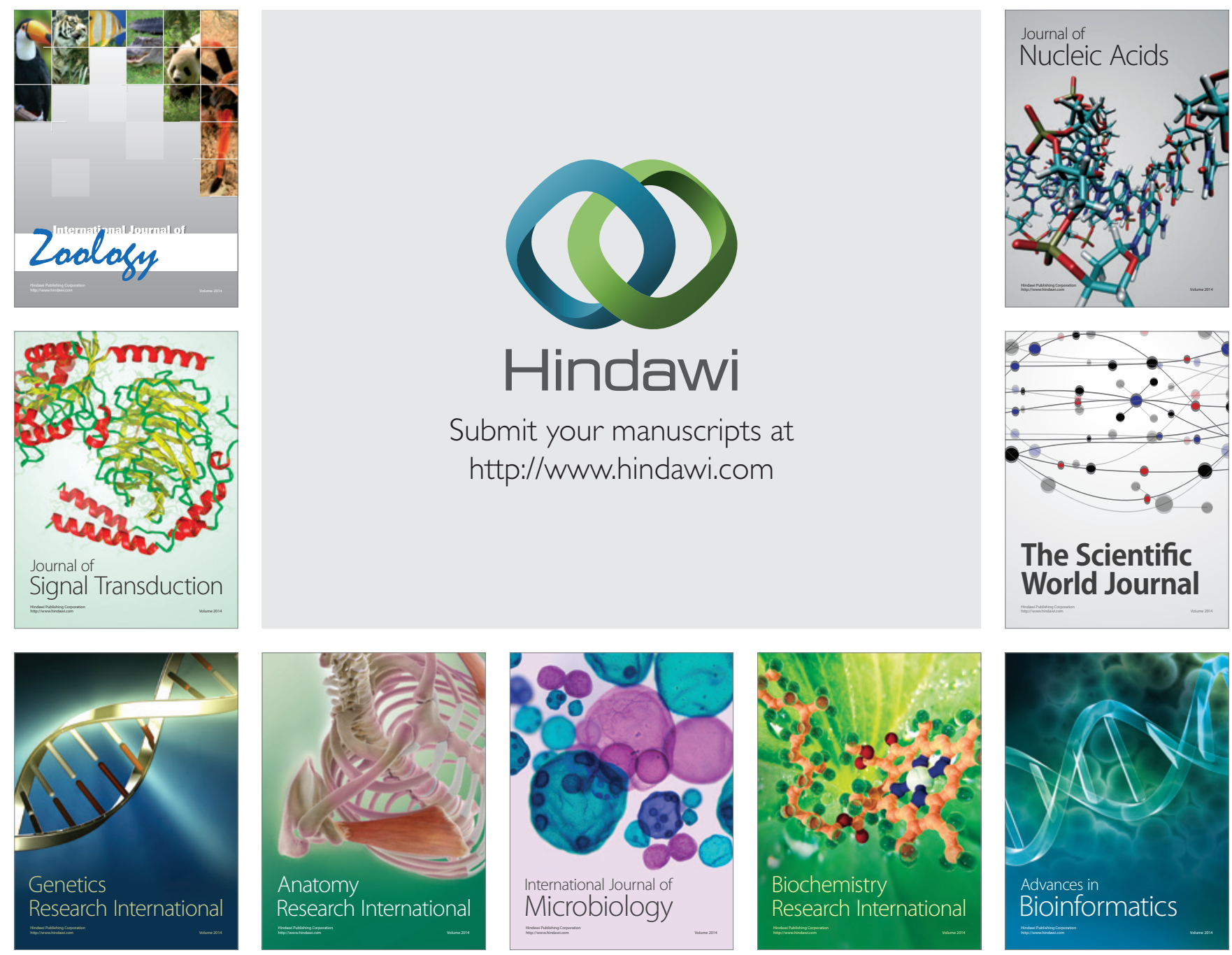

The Scientific World Journal
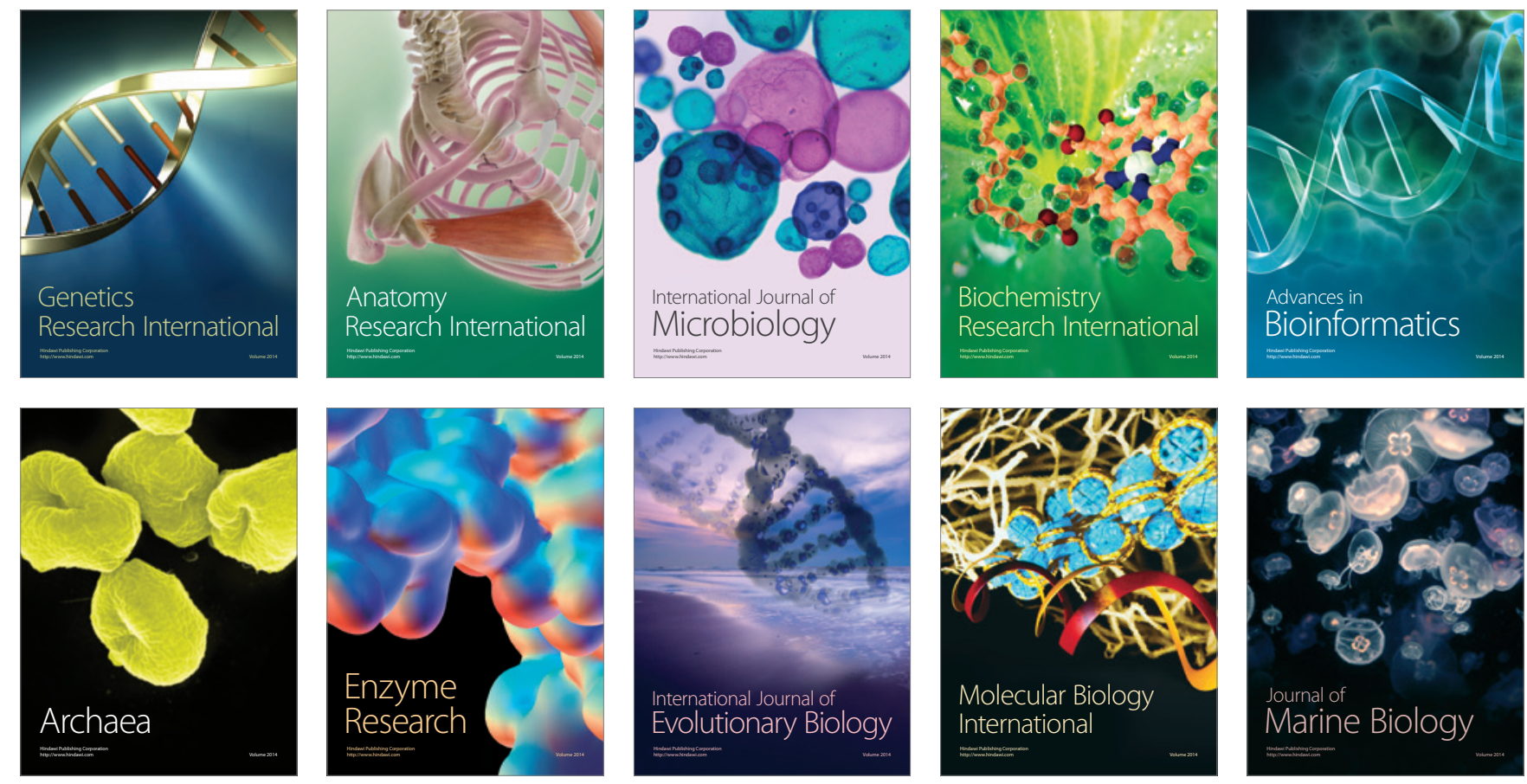